Review article

\title{
Tularemia: emergence/re-emergence
}

\author{
Jeannine M. PETERSEN*, Martin E. SCHRIEFER \\ Bacterial Zoonoses Branch, Division of Vector-Borne Infectious Diseases, \\ National Center for Infectious Diseases, Centers for Disease Control and Prevention, \\ Foothills Campus, PO Box 2087, Ft. Collins, CO 80522, USA
}

(Received 28 May 2004; accepted 9 August 2004)

\begin{abstract}
Francisella tularensis is a gram-negative coccobacillus and the etiologic agent of the zoonotic disease tularemia. First described in 1911 in Tulare County, California, it has since been reported throughout the Northern Hemisphere, with natural infections reported among an unusually wide range of vertebrates and invertebrates. In recent years, tularemia has emerged in new geographic locations, populations, and settings. This review will serve to highlight mechanisms contributing to the recent emergence of tularemia as well as a repertoire of diagnostic tools useful for detecting and diagnosing disease.
\end{abstract}

tularemia / zoonosis / factors of emergence / Francisella tularensis

Table of contents

1. History

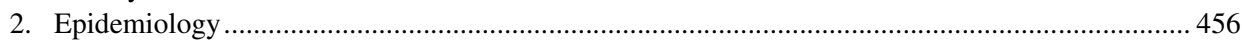

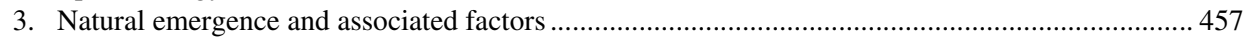

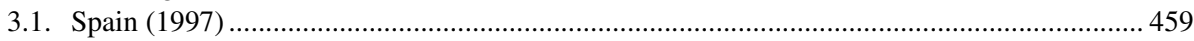

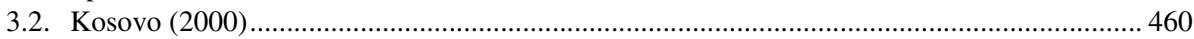

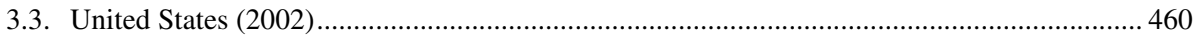

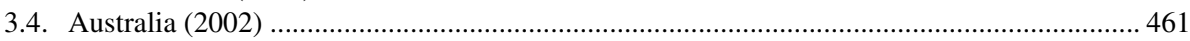

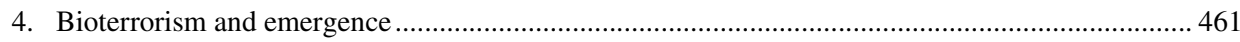

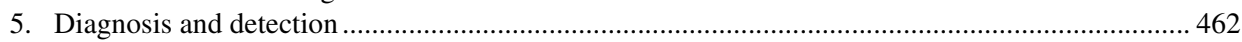

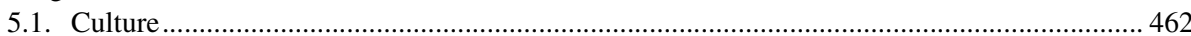

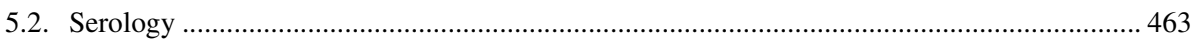

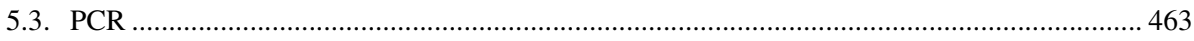

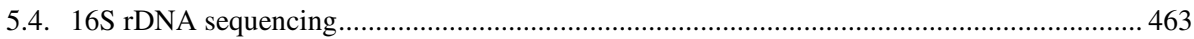

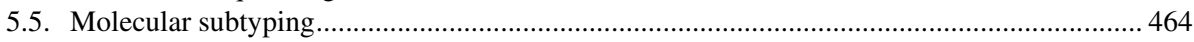

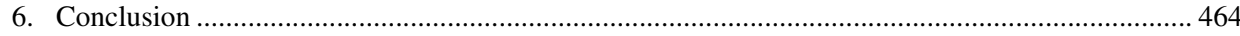

\footnotetext{
* Corresponding author: nzp0@cdc.gov
} 


\section{HISTORY}

Tularemia is a zoonotic disease caused by the small, gram-negative bacterium, Francisella tularensis, one of the most infectious bacteria known, with $<10$ organisms capable of causing severe disease in both humans and animals [23, 60]. First described as a disease of significance nearly a century ago, tularemia has recently emerged in areas with no previous known risk and re-emerged in research and public health circles due to its biothreat potential.

The complexity of $F$. tularensis and its associated disease can be illustrated by a brief review of the early history. In 1911, McCoy and Chapin described a plague-like illness of rodents in Tulare County, California, and soon after (1912) cultured F. tularensis from squirrels in the area [49]. Two years later, the first human illness attributed to $F$. tularensis was described by Wherry and Lamb in Ohio, who isolated the bacterium from two patients with confirmed wild rabbit contact [68]. Subsequently, Edward Francis, for whom the genus is named, established that several clinical syndromes throughout the United States were caused by $F$. tularensis and proposed the name "tularemia" to describe them $[29,30]$. These syndromes included "rabbit fever", "market's men disease" and "meat-cutter's disease", all of which were used to describe the illness associated with dressing rabbits for meat. "Deer-fly fever" was used to describe the disease following a deerfly bite, with most early observations made by Pierce in Utah. "Glandular type of tick fever" was used by physicians in Idaho who noted enlargement of lymph nodes in response to a tick bite.

Until 1925, it was widely believed that tularemia was a disease with risk limited to the United States. This perception soon changed. Ohara, studying hare disease (Yato-byo) in Japan, recognized the similarity of the disease to tularemia and sent specimens to Francis, who confirmed the presence of $F$. tularensis [52]. In the USSR (1928), F. tularensis was recognized as the causative agent of "waterrat-trappers' disease", an illness acquired by trappers who skinned water-rats for their pelts $[62,71]$. Soon thereafter, tularemia was also reported in Norway (1929), Canada (1930), Sweden (1931) and Austria (1935) [31].

\section{EPIDEMIOLOGY}

Today, tularemia is recognized as a widely dispersed disease throughout the Northern Hemisphere with foci in certain parts of North America, Europe, and northern Asia $[23,43]$. Few, if any, zoonotic diseases have a broader or more complex host distribution and epizootiology. F. tularensis infection has been evidenced in a staggering number of wildlife species including various lagomorphs, rodents, insectivores, carnivores, ungulates, marsupials, birds, amphibians, fish and invertebrates [8, 42, 43, 50]. Arthropods, including ticks, biting flies, and possibly mosquitoes, serve as vectors and potentially, long-term reservoirs [8, 24, 42, 44, 50]. Despite the complexity of the global picture of tularemia, the main components of regional disease cycles are much more narrow, typically involving only one to a few, key mammalian and arthropod species.

Two disease cycles, terrestrial and aquatic, have been described $[44,50]$. In the terrestrial cycle, rabbits and hares typically serve as amplifying hosts and ticks or biting flies are arthropod vectors. In the aquatic cycle, beaver, muskrat and voles serve as important mammalian hosts and appear to shed live organisms into their environments. In Sweden, mosquitoes have been strongly implicated as vectors of tularemia and may acquire infection from other components of the aquatic cycle. Curiously, mosquitoes are not thought to be significant contributors to disease transmission in the United States, despite their sharing of the same environments as other components of the aquatic system. Recently, protozoa have been shown to harbor $F$. tularensis and may play an important role in aquatic cycles [1]. The interaction between aquatic and terrestrial cycles is largely unknown. 
F. tularensis has been classified into four distinct subspecies, tularensis, holarctica, mediasiatica, and novicida [60]. The global distribution of disease caused by each subspecies is shown in Figure 1; clearly, subsp. tularensis and holarctica are responsible for the majority of described human and animal illness. Of the four subspecies, subsp. tularensis, also known as Type A, has the highest mortality rate. Infections due to Type A have been limited to North America. In comparison, $F$. tularensis subsp. holarctica, also known as Type B, has been documented throughout the Northern Hemisphere. Thus, in North America, both Type A and Type B are present and often over-lap within a given sub-region. The subsp. novicida and mediasiatica have more focal distributions with mediasiatica isolated only from the Central Asian regions of the former USSR, and novicida isolated from North America and more recently Australia [18, 41, 60, 69]. These two subspecies are infrequently associated with human disease.

Risk factors associated with human disease are linked to local disease ecology. For example, in the Western United States, biting fly exposures, tick bites and animal contact are all significant risks factors [43, 44]. In contrast, human cases in the central United States are rarely linked with biting flies and most often associated with tick bites and animal exposure [43, 44]. Similarly, mosquito exposure is an important risk factor in Sweden, whereas tabanid exposure is more strongly linked to cases in Russia [8].

Clinical presentation of tularemia is variable and dependent on the route of infection $[22,23]$. Presentations include ulceroglandular, glandular, oculoglandular, oropharyngeal, pneumonic and typhoidal forms of tularemia. Ulceroglandular tularemia generally arises from contact with an infected animal or by the bite of an infected vector and is characterized by the presence of an ulcerated lesion and enlargement of regional lymph nodes. This type of exposure is exemplified by cases in a recent outbreak in Spain (described below). Glandular tularemia is quite similar to ulceroglandular disease but lacks the ulcerated site of infection. Oculoglandular tularemia occurs when the conjunctiva is the initial site of infection, usually a result of mechanical transfer of organisms from an infectious source to the eye by the fingers. This form of disease is characterized by the appearance of ulcers and nodules on the conjunctiva and regional lymph node swelling. Oropharyngeal tularemia results from ingestion of contaminated water or food and is characterized by a severe sore throat with enlargement of the tonsils and swollen cervical lymph nodes. Most human cases in the recent outbreak of tularemia in Kosovo (described below) were of this form. Pneumonic tularemia, the most severe form of disease, occurs by direct inhalation of the organism, or may develop secondarily by septicemic spread of infection from a primary site of infection. Historically, farming, and more recently landscaping, have been significant occupational risk-factors associated with pneumonic tularemia in certain endemic areas $[26,63]$. Typhoidal tularemia is used to describe a systemic disease with fever and other constitutional signs in the absence of lymphadenitis, cutaneous lesions, or primary pulmonary involvement.

\section{NATURAL EMERGENCE AND ASSOCIATED FACTORS}

Perhaps Roy Parker best voiced the potential for emergence of tularemia when he said: "I know of no other infection of animals communicable to man that can be acquired from sources so numerous and so diverse. In short, one can but feel that the status of tularemia, both as a disease in nature and of man, is one of potentiality" [54]. With $F$. tularensis being so widespread in wildlife species and the environment, it is poised to appear in new places and populations at any time.

As examples of natural emergence or reemergence of tularemia, three outbreaks 


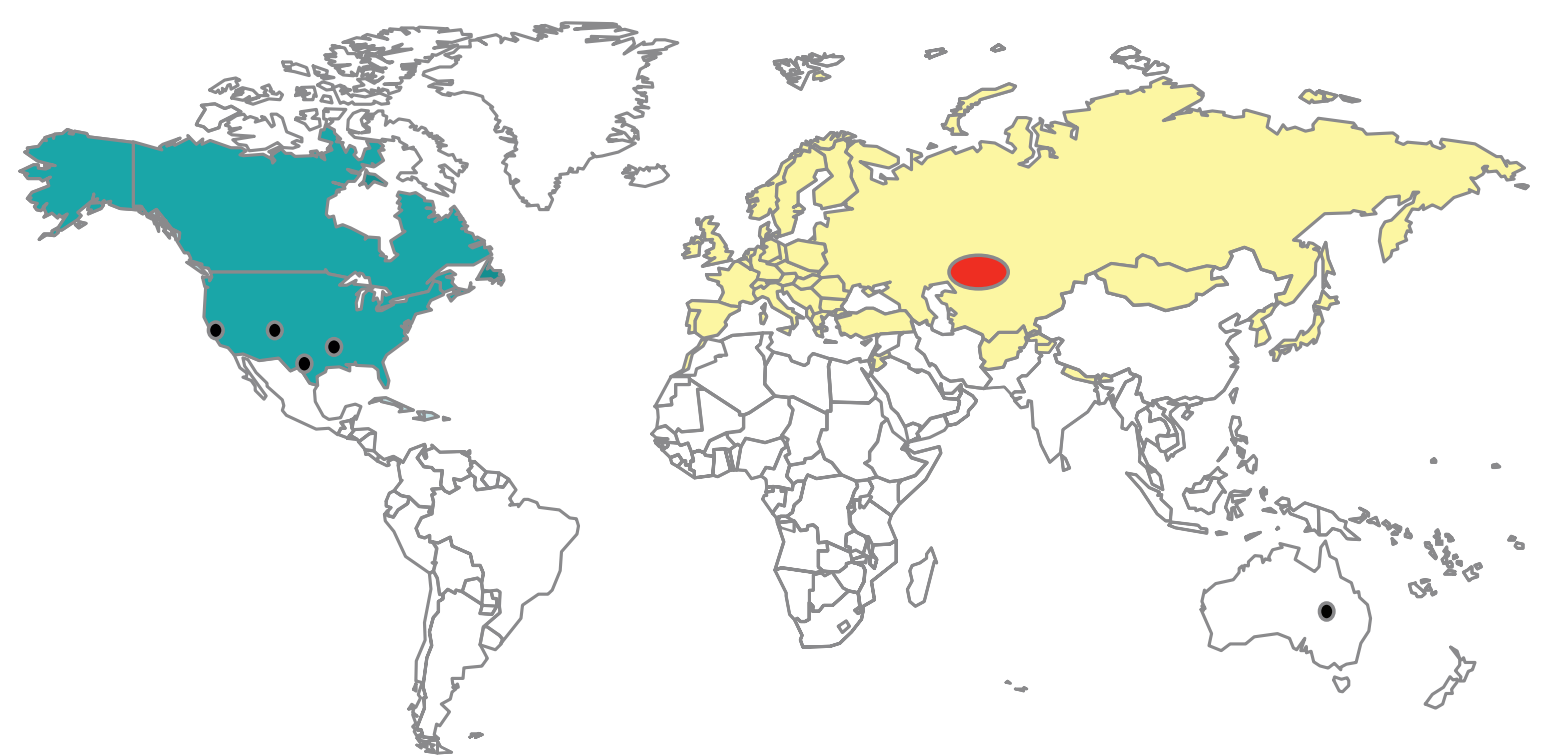

Figure 1. The global distribution of disease caused by $F$. tularensis subspecies. The different shadings represent the distributions of Type A and Type B $(\square)$, Type B $(\square)$, novicida $(\square)$, and mediasiatica $(\square)$. Note that in North America, disease is caused by both subsp. Type A and Type B. 
Table I. Emergence of naturally occurring F. tularensis (1997-2002).

\begin{tabular}{|c|c|c|c|c|}
\hline Site of emergence & Subspecies & Year & Source of infection & Likely basis for emergence \\
\hline $\begin{array}{l}\text { Spain } \\
\text { (Humans) }\end{array}$ & holarctica & $\begin{array}{l}1997 \\
1998\end{array}$ & $\begin{array}{l}\text { Hares } \\
\text { Crayfish }\end{array}$ & $\begin{array}{l}\text { Importation of hares from } \\
\text { endemic countries }\end{array}$ \\
\hline $\begin{array}{l}\text { Kosovo } \\
\text { (Humans) }\end{array}$ & holarctica & 2000 & Food and water & $\begin{array}{l}\text { War conditions/rodent } \\
\text { population increase }\end{array}$ \\
\hline $\begin{array}{l}\text { United States } \\
\text { (Prairie Dogs) }\end{array}$ & holarctica & 2002 & Prairie dogs & $\begin{array}{l}\text { Exotic Pet trade/unregulated } \\
\text { commercial sales of wild-caught } \\
\text { animals }\end{array}$ \\
\hline $\begin{array}{l}\text { Australia } \\
\text { (Human) }\end{array}$ & novicida & 2002 & Water & $\begin{array}{l}\text { Enhanced detection/ } \\
\text { laboratory skills }\end{array}$ \\
\hline
\end{tabular}

and an isolated case will be highlighted in this review (Tab. I) and include: the first evidence of tularemia in Spain (1997) and in Kosovo (2000), the first large-scale outbreak of tularemia in prairie dogs (United States, 2002), and the finding of $F$. tularensis in the Southern Hemisphere (2002). While other examples of tularemia emergence exist, the cases detailed here serve to highlight a variety of mechanisms for disease emergence.

\subsection{Spain (1997)}

Although tularemia has been reported throughout much of Europe, it first emerged as a human disease in Spain in 1997-1998, when a large outbreak occurred $[21,37,55]$. A total of 559 cases of tularemia were reported with 519 cases from the community of Castille-Leon in northwestern Spain. A study of 142 patients in this region indicated that 97.2\% had previous contact with hares; $83.8 \%$ had prepared hare carcasses and $13.3 \%$ had handled hare meat [55]. As expected based on contact with infected animals, ulceroglandular tularemia was the most common form of clinical disease observed (87\% of patients). Type B was isolated from patients and also from hares in the region.

In 1998, a second outbreak of tularemia in humans was reported, this time in the central province of Cuenca, a region distant from the outbreak the previous year [4]. Nineteen cases of ulceroglandular tularemia were identified in persons who had contact with crayfish. This outbreak was most unusual in that tularemia had not previously been associated with fishing. Waterborne outbreaks of tularemia have occurred in the past, but most have been associated with contaminated drinking water $[35,43]$. Transient contamination of the river and crayfish was implicated as the cause of the outbreak, with most patients incurring crayfish-related scratches, cuts, and abrasions while fishing. A sewage plant, which intermittently discharged water into the river, was linked to the cause of the outbreak. Type B, PCR positive samples were obtained from the river, crayfish, and human lymph node aspirates.

It is not clear when tularemia was introduced into Spain. Since tularemia was not recognized as a disease of Spain it would not have been considered in a clinical diagnosis prior to 1997. Nonetheless, evidence suggests that $F$. tularensis was present in Spain before the first outbreak. Retrospective studies have shown the presence of anti-F. tularensis antibodies in humans prior to 1997 and tularemia as the cause of a large hare die-off in the Castille-Leon area in 1994 [27, 34, 37].

The basis for emergence of tularemia in Spain remains speculative, with a likely explanation that infected hares were imported 
from tularemia endemic countries. Every year, hares are imported from Central Europe for hunting purposes and in 1996 tularemia infected hares from France, Italy, Austria, Finland, Sweden and Slovakia were described [5].

Importation of infected rabbits has been attributed to the emergence of tularemia elsewhere in the Northern Hemisphere. In the United States in the 1930s, infected rabbits from the tularemia endemic states, Missouri and Arkansas, were imported by game clubs into Massachusetts and liberated [7]. Soon thereafter the first locally acquired cases of tularemia were reported [3, 7].

\subsection{Kosovo (2000)}

The first report of tularemia in Kosovo occurred in early 2000, at the end of 10 years of political crisis and warfare in the region, when a cluster of patients was identified with an unusual syndrome of fever, pharyngitis and pronounced cervical lymphadenopathy $[59,70]$. Active case-finding and serology testing confirmed 327 cases of tularemia in 21 Kosovo municipalities, with most cases presenting as oropharyngeal tularemia. Ingestion of $F$. tularensis was suspected as the cause of the outbreak and a follow-up case-control study indicated that the outbreak was food and water related [59].

Retrospective analysis of public health records back to 1946 showed no prior evidence of tularemia in Kosovo [59]. Nonetheless, it is possible that tularemia had been present in Kosovo prior to the outbreak, but unrecognized in the absence of a large number of human cases. Both animal and human tularemia had been reported in neighboring countries and independent provinces [59]. In 1976, a five-year ecological study in neighboring Croatia showed that meadow and common voles were foci of tularemia in the region [10]. In addition, tularemia was reported in Turkey in the 1990 s, with the majority of human cases being waterborne $(83 \%$ of cases) $[36,39]$.
The emergence of tularemia in Kosovo is linked to the conditions resulting from war and political crisis [59]. The principal populations affected by the outbreak lived in rural farming villages and had fled their villages in 1999 as a result of ongoing conflict, leaving behind unprotected food storage areas, unharvested crops and plowed, unseeded fields. Untended wells were damaged and contaminated. Returning villagers noted a population explosion of rodents with increased rodent activity apparent both in and around homes. Thus, it is likely that the war time conditions led to increase in the local rodent population which allowed for epizootic spread of tularemia in rodents and consequent widespread environmental contamination.

The consequences of war, damaged public health care systems, unsound hygiene, and rodent increase, set the stage for the emergence and spread of a variety of infectious diseases. Conflict conditions, during World War II and in Bosnia in 1995, have led to previous outbreaks of tularemia $[53,59]$.

\subsection{United States (2002)}

Tularemia is a recognized disease of the United States, yet in 2002 it emerged in a rather unusual and unexpected setting [6, $15,56]$. The site of the outbreak was a Texas exotic pet facility where a variety of animal species were housed together and sold to domestic and international distributors. Thousands of wild-caught prairie dogs were supplied to this facility for commercial purposes and in July 2002 a large die-off ( 250 prairie dogs) occurred. Type $B$ was isolated from the dead prairie dogs at the Texas facility as well as prairie dogs distributed to the Czech Republic and to a Texas pet shop.

In this outbreak, the trade of trapping and selling wild animals as exotic pets allowed disease emergence. Although both tularemia and plague had previously been identified in wild-caught prairie dogs, there were no quarantine restrictions or testing requirements for wild-captured animals, prior to 
their worldwide distribution as pets $[2,13$, 47]. Apparently, one or more infected animals were wild-captured, and the disease spread by cannibalism as a result of the unnaturally close contact at the exotic pet facility. The primary mode of transmission was ingestion of $F$. tularensis, as all infected prairie dogs displayed enlarged submandibular lymph nodes, a hallmark of oropharyngeal tularemia.

In the years prior to this outbreak, the exotic pet trade had experienced growing popularity in the United States with unregulated importation and exportation. Wild prairie dogs, found throughout the Great Plains of North America from southern Canada to just inside Mexico, were collected in the United States between the months of April and July every year and distributed to pet stores throughout the country as well as exported internationally.

In 2003, the Centers for Disease Control and Prevention (CDC) and the Food and Drug Administration (FDA) issued an interim final rule to establish new restrictions on the commercial sale of prairie dogs and the importation of certain exotic species into the United States as the result of a monkeypox outbreak in prairie dogs and subsequent transmission to human owners [16, 17, 58]. Both the tularemia and monkeypox outbreaks in prairie dogs served to highlight the public health dangers associated with the exotic pet trade, including the speed with which infected animals can be transported and the potential for the exotic pet trade to rapidly introduce non native pathogens worldwide.

\subsection{Australia (2002)}

Although $F$. tularensis has long been considered to cause disease in the Northern Hemisphere, in $2002 F$. tularensis subsp. novicida emerged in the Southern Hemisphere with the first report of human infection [69]. A 53-year old man presented with a swollen toe and swollen inguinal lymph nodes as a result of a cut received in brack- ish waters in the Northern Territory of Australia. The toe wound yielded an isolate of $F$. tularensis subsp. novicida. Because $F$. tularensis was not known to be present in the Southern Hemisphere, molecular comparison with other Type A, Type B, and novicida isolates was required before this isolate could be appropriately identified.

As in the case of tularemia in Spain, it's unlikely that this case represents true emergence of F. tularensis in Australia. F. tularensis subsp. novicida is a less virulent subspecies of $F$. tularensis with only a few human cases of tularemia-like illness described worldwide. In addition, tularemia was not recognized as a disease of Australia and would not have been considered in a clinical diagnosis. As a result, the identification of infection due to $F$. tularensis relied heavily on the laboratory's skill and persistence in identifying the isolate. The availability of molecular tools and national and international collaboration contributed to the accurate identification of $F$. tularensis in the Southern Hemisphere.

Interesting questions remain to be elucidated regarding $F$. tularensis in Australia, including how long the organism has been present in Australia and whether there might have been previous unrecognized cases. Nonetheless, this example serves to underscore the likelihood that $F$. tularensis is more widespread than previously thought and elicits the question of whether other $F$. tularensis subspecies are also present in Australia and elsewhere in the Southern Hemisphere.

\section{BIOTERRORISM AND EMERGENCE}

Perhaps the most unique aspect of $F$. tularensis emergence relates to recent worldwide concerns regarding the potential use of biological weapons [40]. Whereas the previous examples all discussed emergence with respect to the appearance of the disease in a new geographic location or population, 
emergence here is used to describe the general public and scientific community awareness of tularemia. Due primarily to concerns over the use of $F$.tularensis as a biological weapon, tularemia has emerged as a widely recognized disease throughout the world. This is in stark contrast to 10 years prior when tularemia was considered to be of negligible public health significance, removed from the United States nationally notifiable list of diseases [14] and recognized only by a few subject matter experts around the world.

F. tularensis has been classified as a Category A select agent, because of its extreme infectivity, ease of dissemination, and substantial capacity to cause illness and death [20]. Heightened concern regarding the intentional use of $F$. tularensis as a bioweapon is also due to its previous history [22]. It was studied by Japanese germ warfare units between 1932 and 1945 and the United States military stockpiled $F$. tularensis for use as a biological weapon in the 1960's. In the 1990s, the Soviets were reported to have produced $F$. tularensis strains with engineered resistance to vaccines and antibiotics.

In the scientific research community, massive amounts of bioterrorism funding are being directed at Category A agents. As a result, more researchers are working with $F$. tularensis than ever before. Numerous laboratories in the United States are studying the biology of this organism, with respect to vaccine development, new diagnostics, and virulence factors.

In public health laboratories around the world, laboratorians are now on the lookout for potential bioterrorism agents. In countries where F. tularensis has not previously been found, microbiologists are now becoming familiar with the protocols to isolate and identify this organism. Awareness of the disease has also increased among the medical community. With this enhanced worldwide surveillance, we may expect to discover $F$. tularensis in new and unexpected places. No doubt bioterrorism awareness contributed to the first identification of F. tularensis in the Southern Hemisphere.

\section{DIAGNOSIS AND DETECTION}

Identification of natural cases of disease emergence is limited by our diagnostic tools, as well as by the skills and attention of clinicians and laboratorians. In this section we will provide a review of the current diagnostics for $F$. tularensis and their importance in understanding disease emergence, as well as some recent advances in diagnostics that may aid in future investigations.

\subsection{Culture}

Culture recovery and characterization remains the "gold standard" for laboratory confirmation of tularemia infection according to the CDC. However, this approach has historically proven itself challenging, particularly with $F$. tularensis subsps., Type A and Type B. F. tularensis subsps., Type A and Type B, are slow-growing, fastidious organisms requiring sulfhydryl compounds and $24-72 \mathrm{~h}$ for growth on artificial media at $37^{\circ} \mathrm{C}[19,60] . F$. tularensis is also notorious for causing laboratory acquired infections and has to be handled under BSL-3 conditions [19,60]. Despite these concerns, culture provides a conclusive diagnosis of infection and an invaluable resource for molecular epidemiology, subtyping and discovery of novel species and subspecies.

$F$. tularensis from primary clinical sources grows well on several media, including enriched chocolate agar (CA), cysteine heart agar with $9 \%$ chocolatized blood (CHAB), and buffered charcoal yeast extract (BYCE) $[19,60]$. F . tularensis can be isolated from nutrient enriched specimens (tissues) on sheep blood agar (SBA), but CHAB is strongly recommended for subculture as the organism will fail to thrive with continued passage on SBA. Additonally, growth on $\mathrm{CHAB}$ provides for presumptive identification of $F$. tularensis as the organism shows 
characteristic growth on this media (green, opalescent, raised, shiny colonies at 24 $48 \mathrm{~h}$ ). Once a pure isolate has been recovered, glycerol fermentation can be used to differentiate Type A (glycerol fermentation positive) and Type B (glycerol fermentation negative). F. tularensis subsp. novicida is non-fastidious and can be isolated on general microbiological agars, including SBA.

Contaminated specimens pose an especially difficult challenge when attempting to isolate $F$. tularensis. Evidence suggests that some bacteria inhibit $F$. tularensis growth [57]. This finding has important implications when attempting to isolate $F$. tularensis from a variety of samples that contain other bacterial species. Recently, an antibiotic supplemented CHAB media (CHAB-A) was shown to significantly improve recovery rates of $F$. tularensis from tissue sources contaminated or overgrown by other flora [57]. In clinical or environmental specimens where mixed flora is likely, the use of CHAB-A should be considered.

\subsection{Serology}

Serology is the most commonly used laboratory approach for confirmation of suspected disease. However, specific antibody responses are typically not detectable prior to two weeks of infection with currently available tests [9]. Nonetheless, retrospective serosurveys can be extremely useful for understanding the timing of disease emergence in a particular area or population. IgM, IgA and IgG antibodies appear simultaneously after initial infection and IgM antibodies can last for many years. Agglutination based on formalin-killed whole cells is the standard serology test used for determining the presence of antibody against F. tularensis [12]. ELISAs based on LPS or outer membrane carbohydrate-protein fractions have also been utilized [9, 67]. With renewed interest in $F$. tularensis due to bioterrorism, we may well expect the identification of new diagnostic antigens useful for early detection and subtyping.

\subsection{PCR}

A variety of PCR methods have been described for the detection of $F$. tularensis DNA in both clinical and environmental specimens. PCR can be an invaluable diagnostic tool when organisms are noncultivable or nonviable. The majority of PCR tests for $F$. tularensis have been gel-based PCR assays targeted at the genes encoding the outer membrane proteins, fopA or tul4 [32, $48,61]$. These PCR assays show good specificity and allow for rapid detection of $F$. tularensis in specimens. The tul4 PCR assay displays a sensitivity of $75 \%$ when applied to wound specimens from patients with ulceroglandular tularemia [45].

Advances in PCR detection have been made with the development of real-time TaqMan PCR assays. These assays have increased specificity and rapidity over gel-based PCR and can provide added sensitivity when testing both clinical and environmental specimens in which the number of organisms is expected to be quite low. A real-time F. tularensis multitarget TaqMan PCR assay based on three targets, the ISFtu 2 element, $23 k D a$ and tul4 genes was recently described [66]. In addition to increased sensitivity, a detection limit of $\sim 1 \mathrm{CFU}$, the multitarget aspect of this assay has the added advantage of decreasing the likelihood of false positives.

\subsection{S rDNA sequencing}

Several studies have shown the usefulness of 16S rDNA sequence identification in the diagnostic laboratory, especially as relates to slow-growing, unusual, and fastidious bacteria $[38,64]$. For identifying true emergence of $F$. tularensis, in areas where it has not previously been reported, $16 \mathrm{~S}$ rDNA sequencing is a particularly useful diagnostic test. 16S rDNA sequencing played an important role in the first identification of $F$. tularensis in the Southern Hemisphere and also in the tularemia outbreak associated with crayfish in Spain [4, 
69]. For identification of recovered bacterial isolates, the universal $16 \mathrm{~S}$ rDNA primers as well as the Francisella specific 16S rDNA primers, provide good sequence data [28]. For diagnostic identification of Francisella spp. in contaminated samples (ticks, water, field specimens), the Francisella specific $16 \mathrm{~S}$ rDNA primers should be considered $[4,51]$.

\subsection{Molecular subtyping}

PCR subtyping assays have been developed that allow for discriminating $F$. tularensis subsp., Type A and Type B, in the absence of a culture $[46,56]$. These assays are gel-based and center on the detection of differences in amplified product sizes. More recently, a gel-based PCR assay targeted at the region of difference 1 (RD1), has been reported to distinguish between all four subspecies of $F$. tularensis, Type A, Type B, novicida, and mediaasiatica, although evaluation of a larger panel of isolates, especially novicida, will be required before this assay can be employed routinely for $F$. tularensis subtyping [11].

Advances have recently been made in strain differentiation using a variety of molecular techniques including restriction fragment linked polymorphism (RFLP) Southern blot, pulsed-field gel electrophoresis (PFGE) and multi-locus variable number tandem repeat assays (MLVA) [25, 33, 65]. These techniques will be extremely important for detailed molecular epidemiology studies in the future. With continued development and refinement of these techniques, we can well expect molecular strain differentiation of $F$. tularensis to play an important role in understanding the true basis of disease emergence.

\section{CONCLUSION}

Renewed scientific and public interest in the field of tularemia has evolved recently in large part due to the biothreat potential of this bacterial agent. Ironically, tularemia was dropped from the list of nationally reportable diseases in the United States in 1994 only to be reinstated in 2000. Although actively investigated in the early 1900's, many of the questions posed during that era are still valid. What are the differences that account for virulence between Type A and Type B strains? Where does tularemia persist during quiescent periods? Is there spillover between aquatic and terrestrial disease cycles? What are the environmental factors that lead to outbreaks in animals and humans? Natural factors influencing the ecology and emergence of tularemia are poorly understood but undoubtedly include climate, numbers of suitable hosts and vectors, and resistance of hosts to infection. Although these parameters may be influenced by man, more immediate outcomes are affected by activities such as the introduction or movement of diseased and susceptible hosts. Recent and novel human outbreaks have served to heighten the awareness, importance, and interest in this complex zoonotic disease. With the aid of current molecular diagnostic tools, tried-and-true bacteriologic methods, increased clinical recognition, epidemiologic investigations and an infusion of research funding, the answers to these questions are well within our grasp.

\section{ACKNOWLEDGEMENTS}

We thank Pedro Anda and Raquel Escudero for information regarding the emergence of tularemia in Spain. We also thank Charles B. Beard, David Withum, Barbara J. Johnson, and Kiersten Meacham for critically reading the manuscript.

\section{REFERENCES}

[1] Abd H., Johansson T., Golovliov I., Sandström G., Forsman M., Survival and growth of Francisella tularensis in Acanthamoeba castellanii, Appl. Environ. Microbiol. 69 (2003) 600 606. 
[2] Alexander J.L., Plague, pet prairie dogs USA (Texas), ProMed. July 10, 1998, http://www.promedmail.org, archive number: 19980710.1303.

[3] Ayres J.C., Feemster R.F., Epidemiology of tularemia in Massachusetts with a review of the literature, N. Engl. J. Med. 238 (1948) 187193.

[4] Anda P., Segura del Pozo J., Diaz Garcia J.M., Escudero R., Garcia Pena F.J., Lopez Velasco M.C., Sellek R.E., Jimenez Chillaron M.R., Sanchez Serrano L.P., Martinez Navarro J.F., Waterborne outbreak of tularemia associated with crayfish fishing, Emerg. Infect. Dis. 7 (2001) 575-582.

[5] Anonymous, Diseases of lagomorphs: tularemia, Office International des épizooties, Sanidad animal mundial en 1996, tomo 1, p. 28.

[6] Avashia S., Petersen J.M., Lindley C., Schriefer M.E., Gage K., Cetron M., Demarcus T.A., Kim D., Buck J., Monteneiri J.A., Lowell J., Antolin M., Kosoy M., Carter L.G., Chu M.C., Hendricks K., Dennis D.T., Kool J.L., Prairie dog to human tularemia transmission, Texas, 2002, Emerg. Infect. Dis. 10 (2004) 483-486.

[7] Belding D.L., Merrill B., Tularemia in imported rabbits in Massachusetts, N. Engl. J. Med. 224 (1941) 1085-1087.

[8] Bell J.F., Tularemia - a review, CRC Handbook Series in Zoonoses, CRC Press, Boca Raton, Section A, 1977, p. 161.

[9] Bevanger L., Maeland J.A., Kvan A.I., Comparative analysis of antibodies to Francisella tularensis antigens during the acute phase of tularemia and eight years later, Clin. Diagn. Lab. Immunol. 1 (1994) 238-240.

[10] Borcic B., Hrabar A., Dulic B., Tvrtkovic N., Bilic V., Mikacic D., Ecological features of the tularemia natural focus in central Posavina (Croatia), Folia Parasitol. (Praha) 23 (1976) 257-265.

[11] Broekhuijsen M., Larsson P., Johansson A., Bystrom M., Eriksson U., Larsson E., Prior R.G., Sjöstedt A., Titball R.W., Forsman M., Genome-wide DNA microarray analysis of Francisella tularensis strains demonstrates extensive genetic conservation within the species but identifies regions that are unique to the highly virulent $F$. tularensis subsp. tularensis, J. Clin. Microbiol. 41 (2003) 29242931.

[12] Brown S.L., McKinney F.T., Klein G.C., Jones W.L., Evaluation of a safranin-O-stained antigen microagglutination test for Francisella tularensis antibodies, J. Clin. Microbiol. 11 (1980) 146-148.
[13] Centers for Disease Control and Prevention, Fatal human plague - Arizona and Colorado, 1996, Morb. Mortal. Wkly. Rep. 46 (1997) 618-620.

[14] Centers for Disease Control and Prevention, Tularemia-United States, 1990-2000, Morb. Mortal. Wkly. Rep. 51 (2002) 182-184.

[15] Centers for Disease Control and Prevention, Outbreak of tularemia among commercially distributed prairie dogs, 2002, Morb. Mortal. Wkly. Rep. 51 (2002) 688-699.

[16] Centers for Disease Control and Prevention, Multistate outbreak of monkeypox-Illinois, Indiana, and Wisconsin, 2003, Morb. Mortal. Wkly. Rep. 52 (2003) 537-540.

[17] Centers for Disease Control and Prevention, Food and Drug Administration, Department of Health and Human Services, Control of communicable diseases; restrictions on African rodents, prairie dogs, and certain other animals. Interim final rule; opportunity for public comment, Fed. Regist. 68 (2004) 62353-62369.

[18] Clarridge J.E. 3rd, Raich T.J., Sjöstedt A., Sandström G., Darouiche R.O., Shawar R.M., Georghiou P.R., Osting C., Vo L., Characterization of two unusual clinically significant Francisella strains, J. Clin. Microbiol. 34 (1996) 1995-2000.

[19] Chu M.C., Weyant R., Francisella and Brucella, in: Murray P.R., Baron E.J., Jorgensen J.H., Pfaller M.A., Yolken R.H. (Eds.), Manual of Clinical Microbiology, 8th ed. American Society for Microbiology, Washington DC, 2003, pp. 789-797.

[20] Darling R.G., Catlett C.L., Huebner K.D., Jarrett D.G., Threats in bioterrorism. I: CDC category A agents, Emerg. Med. Clin. North Am. 20 (2002) 273-309.

[21] De Mateo S., Cosin C.R., Outbreak of tularaemia in Castilla y Leon, Spain, Eurosurveillance Weekly, [on line] (1998) www. eurosurveillance.org/ew/1998/980122.asp.

[22] Dennis D.T., Inglesby T.V., Henderson D.A., Bartlett J.G., Ascher M.S., Eitzen E., Fine A.D., Friedlander A.M., Hauer J., Layton M., Lillibridge S.R., McDade J.E., Osterholm M.T., O'Toole T., Parker G., Perl T.M., Russell P.K., Tonat K., Working Group on Civilian Biodefense, Tularemia as a biological weapon: medical and public health management, JAMA 285 (2001) 2763-2773.

[23] Ellis J., Oyston C.F., Green M., Titball R.W., Tularemia, Clin. Microbiol. Rev. 15 (2002) 631-646.

[24] Eliasson H., Lindback J., Nuorti J.P., Arneborn M., Giesecke J., Tegnell A., The 2000 tularemia outbreak: a case-control study of risk factors 
in disease-endemic and emergent areas, Sweden, Emerg. Infect. Dis. 8 (2002) 956-960.

[25] Farlow J.K., Smith L., Wong J., Abrams M., Lytle M., Keim P., Francisella tularensis strain typing using multiple-locus, variable-number tandem repeat analysis, J. Clin. Microbiol. 39 (2001) 3186-3192.

[26] Feldman K.A., Enscore R.E., Lathrop S.L., Matyas B.T., McGuill M., Schriefer M.E., Stiles-Enos D., Dennis D., Petersen L.R., Hayes E.B., An outbreak of primary pneumonic tularemia on Martha's Vineyard, N. Engl. J. Med. 345 (2001) 1601-1606.

[27] Fernández de Luco et al., Diagnóstico de tularemia por Francisella tularensis en la liebre ibérica (Lepus granatensis) en los años 199498, Abstract book of the X Reunión de la Sociedad Española de Anatomía Patológica Veterinaria, Lugo, 1998, Abstract No. 58.

[28] Forsman M., Sandström G., Sjöstedt A., Analysis of $16 \mathrm{~S}$ ribosomal DNA sequences of Francisella strains and utilization for determination of the phylogeny of the genus and for identification of strains by PCR, Int. J. Syst. Bacteriol. 44 (1994) 38-46.

[29] Francis E., Tularaemia-Francis 1921. The occurrence of tularaemia in nature as a disease of man, Public Health Rep. 36 (1921) 17311738.

[30] Francis E., Tularemia, JAMA 84 (1925) 1243 1250.

[31] Francis E., Sources of infection and seasonal incidence of tularaemia in man, Public Health Rep. 52 (1937) 103-113.

[32] Fulop M., Leslie D., Titball R., A rapid, highly sensitive method for the detection of Francisella tularensis in clinical samples using the polymerase chain reaction, Am. J. Trop. Med. Hyg. 54 (1996) 364-366.

[33] Garcia Del Blanco N., Dobson M.E., Vela A.I., De La Puente V.A., Gutierrez C.B., Hadfield T.L., Kuhnert P., Frey J., Dominguez L., Rodriguez Ferri E.F., Genotyping of Francisella tularensis strains by pulsed-field gel electrophoresis, amplified fragment length polymorphism fingerprinting, and 16S rRNA gene sequencing, J. Clin. Microbiol. 40 (2002) 2964-2972.

[34] García-Peña F.J., Tularemia: description y situación en España de una enfermedad que afecta a 256 especies, Vet. Madrid 42 (1998) 20-29.

[35] Greco D., Allegrini G., Tizzi T., Ninu E., Lamanna A., Luzi S., A waterborne tularemia outbreak, Eur. J. Epidemiol. 3 (1987) 35-38.

[36] Gurcan S., Otkun M.T., Otkun M., Arikan O.K., Ozer B., An outbreak of tularemia in
Western Black Sea region of Turkey, Yonsei Med. J. 29 (2004) 17-22.

[37] Gutierrez M.P., Bratos M.A., Garrote J.I., Duenas A., Almaraz A., Alamo R., Rodriguez Marcos H., Rodriguez Recio M.J., Munoz M.F., Orduna A., Rodriguez-Torres A., Serologic evidence of human infection by Francisella tularensis in the population of Castilla y Leon (Spain) prior to 1997, FEMS Immunol. Med. Microbiol. 35 (2003) 165-169.

[38] Hall L., Doerr K.A., Wohlfiel S.L., Roberts G.D., Evaluation of the MicroSeq system for identification of mycobacteria by $16 \mathrm{~S}$ ribosomal DNA sequencing and its integration into a routine clinical mycobacteriology laboratory, J. Clin. Microbiol. 41 (2003) 1447-1453.

[39] Helvaci S., Gedikoglu S., Akalin H., Oral H.B., Tularemia in Bursa, Turkey: 205 cases in ten years, Eur. J. Epidemiol. 16 (2000) 271276.

[40] Henderson D.A., The looming threat of bioterrorism, Science 283 (1999) 1279-1282.

[41] Hollis D.G., Weaver R.E., Steigerwalt A.G., Wenger J.D., Moss C.W., Brenner D.J., Francisella philomiragia comb. nov. (formerly Yersinia philomiragia) and Francisella tularensis biogroup novicida (formerly Francisella novicida) associated with human disease, J. Clin. Microbiol. 27 (1989) 1601-1608.

[42] Hopla C.E., The ecology of tularemia, Adv. Vet. Sci. Comp. Med. 18 (1974) 25-53.

[43] Hopla C.E., Hopla A.K., Tularemia, in: Beran G.W., Steele J.H. (Eds.), Handbook of Zoonoses, 2nd ed., CRC Press, Inc., Boca Raton, 1994, pp. 113-126.

[44] Jellison W.L., Tularemia in North America, University of Montana, Missoula, Montana, $276 \mathrm{p}$.

[45] Johansson A., Berglund L., Eriksson U., Göransson I., Wollin R., Forsman M., Tärnvik A., Sjöstedt A., Comparative analysis of PCR versus culture for diagnosis of ulceroglandular tularemia, J. Clin. Microbiol. 38 (2000) 22-26.

[46] Johansson A., Ibrahim A., Goransson I., Eriksson U., Gurycova D., Clarridge J.E. 3rd, Sjöstedt A., Evaluation of PCR-based methods for discrimination of Francisella species and subspecies and development of a specific PCR that distinguishes the two major subspecies of Francisella tularensis, J. Clin. Microbiol. 38 (2000) 4180-4185.

[47] La Regina M., Lonigro J., Wallace M., Francisella tularensis infection in captive, wildcaught prairie dogs, Lab. Anim. Sci. 36 (1986) $178-180$. 
[48] Long G.W., Oprandy J.J., Narayanan R.B., Fortier A.H., Porter K.R., Nacy C.A., Detection of Francisella tularensis in blood by polymerase chain reaction, J. Clin. Microbiol. 31 (1993) 152-154.

[49] McCoy G.W., Chapin C.W., Further observations on a plague-like disease of rodents with a preliminary note on the causative agent, Bacterium tularense, J. Infect. Dis.10 (1912) 61-72.

[50] Mörner T., The ecology of tularaemia, Rev. Sci. Tech. Off. Int. Epizoot. 11 (1992) 11231130.

[51] Noda H., Munderloh U.G., Kurtti T.J., Endosymbionts of ticks and their relationship to Wolbachia spp. and tick-borne pathogens of humans and animals, Appl. Environ. Microbiol. 63 (1997) 3926-3932.

[52] Ohara H., Human inoculation experiment with a disease of wild rabbits, with a bacteriologic study, Kinsei Igaku 12 (1925) 401.

[53] Olsulfiev N.G., Rudne G.P., Tularemia, Publishing House for Medical Literature, Moscow, 1960, p. 459.

[54] Parker R.R., Recent studies of tick-borne disease made at the United States Public Health Service laboratory at Hamilton, Montana, in: Proceedings, 5th Pac. Sci. Cong., 1934, pp. 3367-3374.

[55] Perez-Castrillon J.L., Bachiller-Luque P., MartinLuquero M., Mena-Martin F.J., Herreros V., Tularemia epidemic in northwestern Spain: clinical description and therapeutic response, Clin. Infect. Dis. 15 (2001) 573-576.

[56] Petersen J.M., Schriefer M., Carter L.G., Zhou Y., Sealy T., Bawiec D., Yockey B., Urich S., Zeidner N., Avashia S., Kool J., Buck J., Lindley C., Celeda L., Montenieri J., Gage K., Chu M.C., Laboratory analysis of tularemia in wild trapped, commercially distributed prairie dogs, Texas, 2002, Emerg. Infect. Dis. 10 (2004) 419-425.

[57] Petersen J.M., Schriefer M., Gage K.L., Montenieri J.A., Carter L.G., Stanley M., Chu M.C., Methods for the enhanced recovery of Francisella tularensis cultures, Appl. Environ. Microbiol. 70 (2004) 3733-3735.

[58] Reed K.D., Melski J.W., Graham M.B., Regnery R.L., Sotir M.J., Wegner M.V., Kazmierczak J.J., Stratman E.J., Li Y., Fairley J.A., Swain G.R., Olson V.A., Sargent E.K., Kehl S.C., Frace M.A., Kline R., Foldy S.L., Davis J.P., Damon I.K., The detection of monkeypox in humans in the Western Hemisphere, N. Engl. J. Med. 350 (2004) 342-350.

[59] Reintjes R., Dedushaj I., Gjini A., Jorgensen T.R., Cotter B., Lieftucht A., D'Ancona F., Dennis D.T., Kosoy M.A. Mulliqi-Osmani G., Grunow R., Kalaveshi A., Gashi L., Humolli
I., Tularemia outbreak investigation in Kosovo: case control and environmental studies, Emerg. Infect. Dis. 8 (2002) 69-73.

[60] Sjöstedt A., Family XVII. Francisellaceae, Genus I. Francisella, in: Brenner D.J. (Ed.), Bergey's manual of systemic bacteriology, Springer-Verlag, New York, 2005.

[61] Sjöstedt A., Eriksson U., Berglund L., Tärnvik A., Detection of Francisella tularensis in ulcers of patients with tularemia by PCR, J. Clin. Microbiol. 35 (1997) 1045-1048.

[62] Suvarov S., Volfertz V., Voronkova M.M., Plague like lymphadentitis of the Astrikhansky Region, Vestnik Mikrobiol. Epidemiol. Parazitol. 7 (1928) 293.

[63] Syrjala H., Kujala P., Myllyla V., Salminen A., Airborne transmission of tularemia in farmers, Scand. J. Infect. Dis. 17 (1985) 371375.

[64] Tang Y.W., Ellis N.M., Hopkins M.K., Smith D.H., Dodge D.E., Persing D.H., Comparison of phenotypic and genotypic techniques for identification of unusual aerobic pathogenic gram-negative bacilli, J. Clin. Microbiol. 36 (1998) 3674-3679.

[65] Thomas R., Johansson A., Neeson B., Isherwood D., Sjöstedt A., Ellis J., Titball R.W., Discrimination of human pathogenic subspecies of Francisella tularensis by using restriction fragment length of polymorphism, J. Clin. Microbiol. 41 (2003) 50-57.

[66] Versage J.L., Severin D., Chu M.C., Petersen J.M., Development of a multitarget real-time TaqMan PCR assay for enhanced detection of Francisella tularensis in complex specimens, J. Clin. Microbiol. 41 (2002) 5492-5499.

[67] Viljanen M.K., Nurmi T., Salminen A., Enzyme-linked immunosorbent assay (ELISA) with bacterial sonicate antigen for IgM, IgA, and IgG antibodies to Francisella tularensis: comparison with bacterial agglutination test and ELISA with lipopolysaccharide antigen, J. Infect. Dis. 148 (1983) 715-720.

[68] Wherry W.B., Lamb B.H., Infection of man with Bacterium tularense, J. Infect. Dis. 15 (1914) 331-340.

[69] Whipp M.J., Davis J.M., Lum G., de Boer J., Zhou Y., Bearden S.W., Petersen J.M., Chu M.C., Hogg G.G., Characterisation of a novicida-like subspecies of Francisella tularensis isolated in Australia, J. Med. Microbiol. 52 (2003) 839-842.

[70] World Health Organization, Tularemia, Kosovo, Wkly. Epidemiol. Rec. 75 (2000) 133134.

[71] Zarkai G.I., Tularemia among water rats; methods of studying them, Bull. Hyg. 5 (1930) 875 . 